\title{
BULLYING NO AMBIENTE ESCOLAR: UM OLHAR A NOSSA VOLTA
}

\author{
Maria de Fátima Garcia iD1 e Nathany Morais de Souza iD2
}

\section{Resumo}

Este estudo objetiva investigar a prática e as consequências do bullying no ambiente escolar em uma escola pública de ensino localizada no Estado do Rio Grande do Norte, Brasil. A pesquisa, de abordagem qualitativa exploratória, adotou os recursos procedimentais da observação, aplicação de questionário aos alunos e entrevista semiestruturada aos gestores. Ao final do estudo, apontamse alguns resultados, tais como: As práticas de bullying adentram os muros da escola e se fazem presentes na vida dos estudantes de forma traumatizante; Cem por cento dos alunos pesquisados foram vítimas de bullying e destes, quarenta e três por cento relatam se sentirem medrosos e assustados no ambiente escolar enquanto outros silenciam e não revelam aos adultos a perseguição sofrida. E, por fim, trinta e seis por cento afirmaram o desejo de abandonar a escola em decorrência das violências sofridas pelo bullying. Com base nas evidências são apontadas possibilidades de práticas a serem adotadas pela escola com vistas a uma educação emancipatória, sem espaço para qualquer tipo de violência. Vítimas de bullying na infância podem demonstrar comprometimento dos rendimentos escolares, e, possivelmente, há abertura de brechas a transtornos psíquicos na vida adulta em consequência desse tipo de violência, ao que se sugere, em continuidade a esta pesquisa, estudos de caráter longitudinal.

Palavras-chave: Bullying; Escola; Cotidiano Escolar; Vítima; Consequências.

\section{BULLYING IN THE SCHOOL ENVIRONMENT: A LOOK AROUND OUR BACK}

\begin{abstract}
This study aims to investigate the practice and consequences of bullying in the school environment in a public school located in the State of Rio Grande do Norte, Brazil. The research, with an exploratory qualitative approach, adopted the procedural resources of observation, application of a questionnaire to students and semi-structured interviews with managers. At the end study, some results are pointed out, such as: Bullying practices penetrate the walls of the school and are present in the students' lives in a traumatizing way; One hundred percent of the students surveyed were victims of bullying and of these fortythree percent reported feeling fearful and scared in the school environment,

${ }^{1}$ Doutora em Educação. Docente do Departamento de Educação da Universidade Federal do Rio Grande do Norte, Campus CERES / Caicó.

${ }^{2}$ Graduanda em Pedagogia pela Universidade Federal do Rio Grande do Norte, Campus CERES / Caicó.


while others remain silent and do not reveal the persecution suffered to the adults. And, finally, thirty-six percent said they wanted to leave school as a result of violence suffered by bullying. Based on the evidence, possibilities of practices to be adopted by the school are pointed out, with a view to an emancipatory education, with no room for any kind of violence. Victims of bullying in childhood may demonstrate compromised school performance, and possibly there are gaps for psychological disorders in adulthood as a result of this type of violence, which is suggested, in continuity with this research, longitudinal studies.

Keywords: Bullying; School; Daily School; Victim; Consequences.

\section{Introdução}

Este estudo objetiva investigar a prática do bullying no ambiente escolar, ao mesmo tempo em que analisa as consequências geradas em suas vítimas. Sabe-se que o bullying se constitui por um tipo de violência bastante difundida e apercebida mundialmente, embora, contraditoriamente, pouco estudado. Sendo um tema recente em termos de pesquisas clínicas e acadêmicas, é notório que essa prática pode refletir negativamente por todo processo de escolaridade, podendo-se alcançar fases da vida adulta. Portanto, é de grande importância considerar o bullying um problema, cuja necessidade em debatê-lo é relevante, e a escola, como uma instituição social, deve abarcar responsabilidades junto às famílias.

Embora o termo bullying, hoje, seja do conhecimento de muitos, até mesmo das crianças, no Brasil, o combate a esse tipo de violência só surge por meio da Lei n. 13.185, de 06.11.2015 que, por sua vez, foi "considerado um marco jurídico de combate ao bullying e a primeira lei nacional que tem como objetivo prevenir e combater a prática da intimidação sistemática no País" (IBGE, 2016, p. 70). Essa tomada de conhecimento tardio por parte da população, implica na não valorização do tema que, em consequência, passa a não ser tão bem trabalhado nas instituições de ensino.

Nesse contexto, a falta de informação ou falta de bons esclarecimentos, faz com que as vítimas dessa violência continuem aumentando sem que haja qualquer providência maior. Segundo Lopes (2005, p. 12): "o fenômeno bullying é complexo e de difícil solução portanto é preciso que o trabalho seja continuado". Em razão disso, faz-se necessário adentrar melhor a esse campo, a fim de entender como se constrói tal prática e o porquê da sua ocorrência.

$\mathrm{O}$ estudo visa investigar o bullying que percorre a Escola $\mathrm{X}^{1}$ localizada no Estado do Rio Grande do Norte, Brasil, por meio da observação de uma turma do 40 ano do Ensino Fundamental, ao mesmo tempo em que se analisa as consequências na vida escolar dos discentes. A pesquisa utiliza instrumentos de cunho qualitativo tais como entrevistas e questionários que viabilizam a compreensão da temática e análises de dados. Tem como finalidade responder

${ }^{1}$ Utilizaremos o termo Escola $X$ ao longo do artigo por medidas que resguardam a identidade da escola pesquisada.

Perspectivas em Diálogo, Naviraí, v. 09, n. 19, p. 140-158, jan./abr. 2022. 
a seguinte problemática: "Quais as consequências e prejuízos que o bullying pode provocar na vida do discente e, mais especificamente, como a escola pode se aparelhar para combater o bullying em seu cotidiano?"

O artigo divide-se em cinco secções: A primeira intitulada "Bullying: aspectos conceituais e descritivos"; A segunda, "O bullying no ambiente escolar", apresenta o conceito de bullying juntamente com a sua caracterização, posteriormente assinalando suas consequências na vida escolar do discente, indicando o perfil de vítima e do agressor. No terceiro momento, a secção "Metodologia" faz uma abordagem de como foi traçado o caminho da pesquisa realizada, apontando a abordagem, os procedimentos e seu discorrer, subdividindo-se na subsecção intitulada Análise quando, então, se promove diálogos com os dados coletados, em entrelaçamento com os aportes teóricos, tais como Bandeira e Hutz (2007) que apontam questões importantes sobre o bullying, ao tratar sobre a sua prevalência e implicações, Barros; Carvalho e Pereira (2012), Almeida (2007) e Silva (2010) que também contribuem ao trazer discussões acerca da temática, principalmente, no contexto escolar, além de Souza e Gonçalves (2021) que destacam a gordofobia como uma configuração do bullying.

Na secção "Resultados e Possibilidades", são apontadas as evidências do estudo e, na sequência, sugeridas ações para a escola se aparelhar e combater as práticas de bullying. Por fim, nas "Considerações Finais", resgatam-se os pontos iniciais ao trazer à tona o bullying associado ao contexto escolar e suas consequências.

\section{Bullying: aspectos conceituais e descritivos}

Com o propósito de discutir a temática do bullying, é importante identificar o Brasil como um país diverso, o que se constata pela diversidade dos elementos que concebem a identidade brasileira, tais como as diferenças de raça, cor, etnia, classe econômica e cultura da sua população. E é a partir desses fatores que, infelizmente, o Brasil se destaca pelo racismo e preconceito, construídos historicamente, permanecendo enraizados na mentalidade da sociedade.

Os currículos escolares e o cotidiano escolar, no entanto, em grande parte das escolas, (ainda) se contrapõem a essa identidade brasileira constituída pelas culturas negras, indígenas e classes sociais de trabalhadores e trabalhadoras, que tiveram pouco ou nenhum acesso à educação formal. Esses cotidianos escolares se balizam por concepções de educação eurocentrizadas, conteúdos, conceitos e práticas que legitimam a competição, a violência, o racismo e o bullying, praticados por aqueles que se enxergam a partir de concepções supremacistas numa relação desigual com outros que são vistos como inferiorizados e subalternizados, propícios a serem as vítimas de práticas opressoras.

Diante disso, o preconceito seria "[...] a opinião formada a respeito de algo ou de alguém, sem cautela, de maneira açodada, em um julgamento precipitado - e por isso invariavelmente injusto - que provoca aversão a determinadas pessoas ou situações" (SAVAZZONI, 2015, p. 42). Assim, diferenciando-se do 
conceito de bullying que se constitui, segundo Silva (2010, p. 7), como sendo "[...] atos de violência (física ou não) ocorrem de forma intencional e repetitiva contra um ou mais alunos que se encontram impossibilitados de fazer frente às agressões sofridas. Tais comportamentos não apresentam motivações específicas ou justificáveis". Enquanto o preconceito se destaca por um comportamento que gera uma ação resultante da aversão e, por vezes, do ódio, o bullying tem o objetivo de intimidar um certo indivíduo, por se caracterizar como "fraco" diante do agressor. Mas ambos os conceitos podem se interseccionalizar, pois alguém que seja alvo de um preconceito pode vir a ser também alvo do bullying, já que o bullying tem muitas vezes como ponto de partida o preconceito.

O caminho teórico-metodológico trilhado perpassou a revisão da literatura com base nas ideias de autores que tratam da temática bullying como: Lopes (2005) ao verificar esse fenômeno como um comportamento agressivo e, ao mesmo tempo, trazer uma discussão sobre a questão; Silva (2010) por demonstrar, em uma cartilha, aspectos do bullying buscando trazer informações a respeito desse problema, e alertas de forma direta e sucinta, ademais, com pretensão de informar acerca da sua complexidade; Barros; Carvalho e Pereira (2009) por trazerem um maior enfoque sobre a presença desse tipo de violência em um contexto exclusivamente escolar; Jahnke; Gaglietti (2012) por evidenciarem a complexidade do bullying além dos muros da escola, tratando dessa prática extensiva à que se estende para a rede mundial de computadores, caracterizada como cyberbullying, praticado nas redes sociais e na Internet em geral; Almeida (2007) porque nos mostra a relevância do meio como ambiente influenciador e importante diante dos fatores cognitivos. Souza e Gonçalves (2021) ao acrescentar discussões sobre a gordofobia no espaço escolar e, Freire (1996) por alertar acerca da importância da pesquisa em paralelo com a educação, reiterando a importância de problematizar o contexto de atuação, o ensino e a necessidade da pesquisa:

Não há ensino sem pesquisa e pesquisa sem ensino. [...] Enquanto ensino continuo buscando, reprocurando. Ensino porque busco, porque indaguei, porque indago e me indago. Pesquiso para constatar, constatando, intervenho, intervindo educo e me educo. Pesquiso para conhecer o que ainda não conheço e comunicar ou anunciar a novidade (FREIRE, 1996, p. 29)

Entende-se a pesquisa como um possibilitador do entendimento do contexto, imprescindível para a elaboração de conhecimentos, reflexões e práticas envolvendo temáticas que requerem problematização de caráter científico, portanto, contribuindo, para a busca de soluções para o problema. A prática do bullying é comum no ambiente escolar por ser um lócus que abriga um vasto grupo de indivíduos com particularidades, pressupondo-se, assim, um local propício para essa prática que pode ser vista em formas de agressão física com o uso de socos, empurrões, tapas etc., e psicológica como xingamentos, apelidos, isolamento, desprezo e situações constrangedoras. 
Em paralelo, esse fenômeno também não pode ser confundido com a violência escolar, pois esta última se caracteriza por violências decorrentes de desentendimentos entre colegas, furtos e outros motivos que não ocorrem com frequência e nem há perseguição de uma pessoa em específico, ou seja, ao contrário do bullying, que é uma prática que ressalta a persistência em ferir alguém seja psicologicamente ou fisicamente, haja vista que, o fenômeno transcorre por um longo período de tempo. Em função disso, a prática se inicia quando o agressor seleciona sua vítima que, para ele, caracteriza-se como alvo fácil.

As vítimas, de forma geral, já apresentam algo que destoa do grupo (são tímidas, introspectivas, nerds, muito magras; são de credo, raça ou orientação sexual diferente etc.). Este fato por si só já as torna pessoas com baixa autoestima e, portanto, são mais vulneráveis aos ofensores. Não há justificativas plausíveis para a escolha, mas certamente os alvos são aqueles que não conseguem fazer frente às agressões sofridas (SILVA, 2010, p. 8).

Esses atributos que levam o agressor a eleger sua vítima, em muitos casos não são os motivos do bullying, mas essas características podem se destacar como ponto fraco da vítima perante o olhar do agressor, deixando transparecer como uma fraqueza que abre brechas para machucá-la.

Umas das características que tornam o sujeito susceptível a se tornar vítima de bullying é o sobrepeso e a obesidade. A gordofobia que, para Souza e Gonçalves (2021), "[...] é um fenômeno social, que também se manifesta no campo escolar, pode ser relacionada como interposição ao desenvolvimento humano, tanto no campo social, quanto no educacional e cultural, tornando-a um problema da escola [...]", pode ser também considerada bullying, haja vista a presença da perseguição e da violência, que são impulsionadas pelo peso da vítima. Logo, essas características geram estigmas que frequentemente se associam ao baixo desempenho, desleixo, preguiça dentre outras concepções gordofóbicas a respeito dessas pessoas.

Algumas características físicas, comportamentais ou emocionais podem torná-lo mais vulnerável às ações dos autores e dificultar a sua aceitação pelo grupo. A rejeição às diferenças é um fato descrito como de grande importância na ocorrência de bullying. No entanto, é provável que os autores escolham e utilizem possíveis diferenças como motivação para as agressões, sem que elas sejam, efetivamente, as causas do assédio (LOPES, 2005, p. 7).

É inegável que essa violência tenda a percorrer a vida de muitos indivíduos dentro da escola, e que diversas vezes o assunto é calado e encarado como inabitual, de pouca relevância e seriedade. Porém, a sua dimensão é bem maior, o medo se espalha pelos corredores, pátios, banheiros e salas de aula, onde vítimas se calam diante dessa barbárie.

Os espaços onde geralmente ocorre esse tipo de violência são os que estão longe dos olhares dos adultos, neles há um ponto de interação maior entre as 
crianças que compõem a escola e, assim, facilita a ação do agressor. Então, o agressor se utiliza da oportunidade do lugar e circunstâncias favoráveis para colocar em prática seus desejos de se reafirmar em detrimento da vítima. 0 autor da agressão possui um perfil que se sobressai ao da vítima.

Os agressores, acham que todos devem realizar suas vontades, e por uma orientação ou educação pouco adequada, querem ser o centro das atenções. Sentem-se recompensados, mesmo que em curto prazo, por obterem status, poder ou objetos materiais que Ihe eram desejáveis, portanto sentem prazer em estar na situação ou no papel que desempenham durante as ações de ameaças, agressões ou ridicularizarão das vítimas (BARROS; CARVALHO e PEREIRA, 2009, p. 7).

Como resultado desse cenário de agressão, a Pesquisa Nacional de Saúde Escolar (PeNSE) divulgada pelo Instituto Brasileiro de Geografia e Estatística (IBGE) mostra o percentual de escolares que informaram situações de insegurança, violência física ou psicológica. A respeito dos fortemente feridos, pelo menos uma vez, revela-se que $12,3 \%$ responderam afirmativamente. Esse indicador foi de $14,0 \%$ entre os escolares do sexo masculino e de $10,7 \%$ entre os do sexo feminino. O percentual de estudantes de escolas públicas que foram feridos é de aproximadamente $12,7 \%$ e de escolas privadas, 9,7\%.

O fato de a criança se tornar uma agressora, depende de todo um contexto, no qual se vê inserida, pois, não é apenas um fator que leva a criança a praticar esse tipo de violência, mas, um conjunto de aspectos que influenciam na sua formação enquanto sujeito, somando-se a isso, a quebra de regras, valores, desrespeito são características comuns do agressor.

Algumas condições familiares adversas parecem favorecer 0 desenvolvimento da agressividade nas crianças. Pode-se identificar a desestruturação familiar, o relacionamento afetivo pobre, o excesso de tolerância ou de permissividade e a prática de maustratos físicos ou explosões emocionais como forma de afirmação de poder dos pais (LOPES, 2005, p. 8).

Diante das condições que interferem na formação de um caráter agressivo, o agressor se torna alguém que para Lopes (2005) seria forte em comparação aos seus alvos, agressivo e impulsivo, com uma grande necessidade de se reafirmar como alguém superior, assim, amedrontando e ferindo a vítima prazerosamente. Além disso, com a tendência de ter índices acadêmicos baixos e de se impor de maneira rebelde durante as aulas e com as autoridades que 0 rodeia, como os professores.

Quando se tem o apoio indireto dos demais, ou seja, quando o ato é visto por terceiros e não há nenhuma intervenção, acaba por contribuir para a reafirmação do agressor como mais forte dotado de superioridade frente aos demais. Tal contexto, aumenta também sua indisciplina, já que essas testemunhas o veem como ameaça, a qual devem temer e venerar. Gera-se, desse modo, uma criança cujas regras e autoridades se tornam totalmente 
obsoletas. O bullying desestrutura a vida de muitos indivíduos e, em vários sentidos, poderá estar presente em curto, médio ou longo prazo na vida escolar do sujeito, como também na vida pessoal.

\section{O bullying no ambiente escolar}

O primeiro a relacionar a denominação a um fenômeno foi Olweus (1998), no fim da década de 1970, depois de analisar a possibilidade de os recorrentes suicídios da época possuírem relação com esse tipo de violência. A escola, apesar de ser um lócus que, dever-se-ia pressupor princípios que englobam as diversas dimensões humanas buscando trabalhar valores, questões sociais, uma produção científica inerente a formação acadêmica do indivíduo, e uma harmonia com o coletivo, ela, infelizmente, constitui-se pelo berço dos problemas e desajustes sociais que acabam por refletir no processo de ensino-aprendizagem dos estudantes.

É na escola que se constroem as relações que, por sua vez, são importantes para a formação do ser humano enquanto ser social. O homem por ser sociável possui a tendência a se relacionar, mas, tais interações podem fomentar conflitos e divergências, Almeida (2007, p. 85) afirma que "no campo da constituição da pessoa, o conflito entre o eu e o outro, ocorrido do período personalista, revela-se como um grande empreendedor do desenvolvimento do eu". Na infância isso já se torna evidente, mas também preocupante, principalmente quando as relações se conturbam e um dos motivos para a concretização disso é o bullying. Isso ocorre quando os pequenos e raros conflitos tomam maiores dimensões e se tornam fatigantes e intoleráveis e passam a interferir negativamente na vida da criança.

É incalculável o quanto a violência pode trazer consequências para a vida da vítima, esta que, muitas vezes, pode deixar passar por despercebida pelo seu forte envolvimento com o medo que se concretiza desde o início dessa perseguição, e por esse motivo, se cala e guarda esses momentos para si, porém, muitos sinais são evidentes e refletem em sua conduta.

No recreio encontram-se isoladas do grupo, ou perto de alguns adultos que possam protegê-las; na sala de aula apresentam postura retraída, faltas frequentes às aulas, mostram-se comumente tristes, deprimidas ou aflitas; nos jogos ou atividades em grupo sempre são as últimas a serem escolhidas ou são excluídas; aos poucos vão se desinteressando das atividades e tarefas escolares; e em casos mais dramáticos apresentam hematomas, arranhões, cortes, roupas danificadas ou rasgadas (SILVA, 2010, p. 10).

Temer a escola e olhar esse ambiente como desagradável é um sinal comum entre as crianças que sofrem esse tipo de violência, a partir disso, levando-se em consideração o tempo que a criança está sendo alvo, a tendência é começar a sentir os piores problemas da interferência do bullying. 
Os problemas mais comuns são: desinteresse pela escola; problemas psicossomáticos; problemas comportamentais e psíquicos como transtorno do pânico, depressão, anorexia e bulimia, fobia escolar, fobia social, ansiedade generalizada, entre outros. O bullying também pode agravar problemas preexistentes, devido ao tempo prolongado de estresse a que a vítima é submetida. Em casos mais graves, podem-se observar quadros de esquizofrenia, homicídio e suicídio (SILVA, 2010, p. 9).

Nesse contexto, a curto prazo, ainda em sua jornada escolar é comum a presença de tais sinais que se tornam mais preocupantes quando tomam maiores dimensões, haja vista que, esses efeitos serão notados na queda do índice acadêmico do aluno, isto é, na diminuição da participação nas aulas e atividades, sejam em grupo ou individual, falta de atenção, ausência das aulas. Além disso, as relações interpessoais são afetadas já que há o isolamento por parte do autor do bullying e, posteriormente, por parte da própria vítima, logo, afetando em seu ciclo de amizades e suas relações com os demais colegas se tornam mais restritas.

Jahnke e Gaglietti (2012) ressaltam que essa prática vai além da escola, as vítimas podem ser agredidas tanto nesse contexto, como também nas redes sociais, sendo que estas tornam-se quase uma extensão da vida real. Assim, quando a perseguição passa a ser ao mesmo tempo na escola e nas redes sociais, pela via da internet, esse tipo de bullying é denominado de cyberbullying.

A paz fora da escola também deixa de existir, pois os agressores por não se contentarem com tamanha perversidade também fazem forte intimidação por meio dos celulares e computadores, caracterizando-se tal comportamento como uma forma de agressão mais psicológica e abusiva por meio de mensagens de mau gosto, fotos que intimidam e envergonham a vítima em claro atentado a sua dignidade humana, além de fortes e constantes ameaças.

O bullying juntamente com seus seguimentos, permite que essa violência se espalhe e se intensifique ainda mais, fazendo com que a criança que hoje sofre e cultiva as consequências, torne-se o adulto de amanhã que levará consigo as marcas da violência física e psicológica ao longo da vida, podendo se estender para o seu trabalho, o levando ao insucesso profissional, ao comprometimento da saúde psicológica, resultando em indivíduos depressivos e ansiosos.

Assim, é essencial a atenção e um olhar diferenciado para esse tipo de violência, com ênfase nas práticas punitivas e o subsídio na lei de prevenção e combate ao bullying. À vista disso, de acordo com a Lei no 13.185 de 6 de novembro de 2015, que Institui o Programa de Combate à Intimidação Sistemática (Bullying), 
Art. 10 Fica instituído o Programa de Combate à Intimidação Sistemática (Bullying) em todo o território nacional.

Art. 60 Serão produzidos e publicados relatórios bimestrais das ocorrências de intimidação sistemática (bullying) nos Estados e Municípios para planejamento das ações.

Art. $5^{\circ}$ É dever do estabelecimento de ensino, dos clubes e das agremiações recreativas assegurar medidas de conscientização, prevenção, diagnose e combate à violência e à intimidação sistemática (bullying). (BRASIL, 2015).

Sabe-se que não apenas o Brasil, mas o mundo todo já reuniu experiências suficientes para compreender que o bullying é uma ameaça à integridade física e psicológica de crianças e jovens, e por isso, o ambiente escolar se torna um território perigoso caso, gestores e educadores não entendam a diferença entre a brincadeira saudável e a perversidade. E a Lei 13.185/2015 é o amparo legal para que as escolas tomem as medidas cabíveis, em concomitância com a educação antibullying que deve permear todas as ações do projeto pedagógico da unidade escolar.

\section{Metodologia}

A metodologia da pesquisa empregada neste estudo é de caráter qualitativo quanto à abordagem e exploratória quanto aos objetivos. A pesquisa qualitativa foi optada pela sua devida importância no processo de pesquisa e pelas suas características relevantes, enumeradas a seguir:

10) A pesquisa qualitativa tem o ambiente natural como fonte direta dos dados e o pesquisador como instrumento-chave; $2^{\circ}$ ) A pesquisa qualitativa é descritiva; $3^{\circ}$ ) Os pesquisadores qualitativos estão preocupados com o processo e não simplesmente com os resultados e o produto; $4^{\circ}$ ) Os pesquisadores qualitativos tendem a analisar seus dados indutivamente; $5^{\circ}$ ) O significado é a preocupação essencial na abordagem qualitativa [...] (TRIVIÑOS, 1987 , p. 128-130).

Outrossim, é que a pesquisa qualitativa busca percorrer o ambiente social que é a escola, na qual o envolvimento entre pesquisador e objeto é presumível, já que mesmo que intencionalmente busque-se a neutralidade, isso não dará procedência. Nesse contexto, a realidade e o sujeito são indissociáveis, assim, neste tipo de pesquisa leva-se em conta as relações e o contexto ao qual os indivíduos estão inseridos.

No que refere à coleta dos dados, foram utilizados a técnica de observação, diário de campo, questionários e entrevistas semi-estruturadas. A observação, segundo Gil (1999), nada mais é que o uso do sentido com a finalidade de adquirir conhecimentos necessários ao cotidiano, mas que pode servir também de procedimento científico, uma vez que colabora com os objetivos da pesquisa, é sistematicamente planejado e submetido a verificações segundo o rigor científico. Logo, foram realizados registros em Diário de Campo de aspectos e 
comportamentos entendidos como essenciais no que consiste à elaboração da empiria. A observação, cuja duração foi de quatro horas por aula, consistiu em registrar o ambiente escolar com foco nas práticas de bullying.

A pesquisa contou com 15 sujeitos, alunos do $4^{\circ}$ ano do Ensino Fundamental, com idades entre 9 e 12 anos. Observou-se as relações estabelecidas entre as crianças em três ambientes distintos: Durante a aula (em sala de aula), recreação (no pátio) e a educação física. O levantamento da empiria se deu em três momentos, tendo sido destacados os comportamentos que, em sua essência, mostraram-se tendenciosos a serem possíveis casos de bullying.

O primeiro momento visava ao que se denominou como Aproximação à escola, aos alunos, professores e gestoras, e, também, primeira observação exploratória da cultura do local, e das relações sociais ali estabelecidas entre as crianças.

Em um segundo momento, retornou-se com a finalidade de coletar dados que contribuíssem para conceder maior confirmação ao que foi observado. Primeiramente, foi aplicado um questionário a todas as crianças da turma do quarto ano, constituído por sete perguntas, com respostas de múltipla escolha, em cujos campos deveria ser assinalado um " $X$ ", todas com a finalidade única de identificar o bullying nesse contexto, sua interferência, seu proceder e suas consequências. Segundo Gil:

Pode-se definir questionário como a técnica de investigação composta por um conjunto de questões que são submetidas a pessoas com o propósito de obter informações sobre conhecimentos, crenças, sentimentos, valores, interesses, expectativas, aspirações, temores, comportamento presente ou passado etc. (GIL, 1999, p. 121).

Em um terceiro momento, foi utilizado outro instrumento de cunho qualitativo: uma entrevista com a vice-diretora, cuja fala acrescentaram elementos de compreensão importantes na formulação e na discussão do trabalho, o que nos faz concordar com Gil quando este afirma:

A intensa utilização da entrevista na pesquisa social deve-se a uma série de razões, entre as quais cabe considerar: a) a entrevista possibilita a obtenção de dados referentes aos mais diversos aspectos da vida social; b) a entrevista é uma técnica muito eficiente para a obtenção de dados em profundidade acerca do comportamento humano; c) os dados obtidos são suscetíveis de classificação e de quantificação (GIL, 1999, p. 110).

Nesse sentido, os instrumentos utilizados neste trabalho oportunizaram a análise de dados e o levantamento de discussões na perspectiva da temática abordada, logo, compuseram a investigação de falas, fatos e opiniões dos 
participantes que podem ser vistos na subsecção seguinte intitulada de "Análise".

\subsection{Análise}

A pesquisa, conforme dito anteriormente, foi desenvolvida com 15 sujeitos participantes, escolhidos aleatoriamente, que responderam ao questionário aplicado em sala de aula. Diante disso, viu-se a necessidade de entender as relações interpessoais desses estudantes, com o intuito de obter respostas que poderiam identificar aquele ambiente como um lócus envolvido por agressões, humilhações, xingamentos, perseguições que remetessem à presença do bullying.

Em paralelo, a primeira pergunta do questionário possuía a intenção de identificar se alguns deles já havia presenciado, isto é, testemunhado a prática do bullying na sua escola.

\section{Gráfico 1 - Testemunho de bullying}

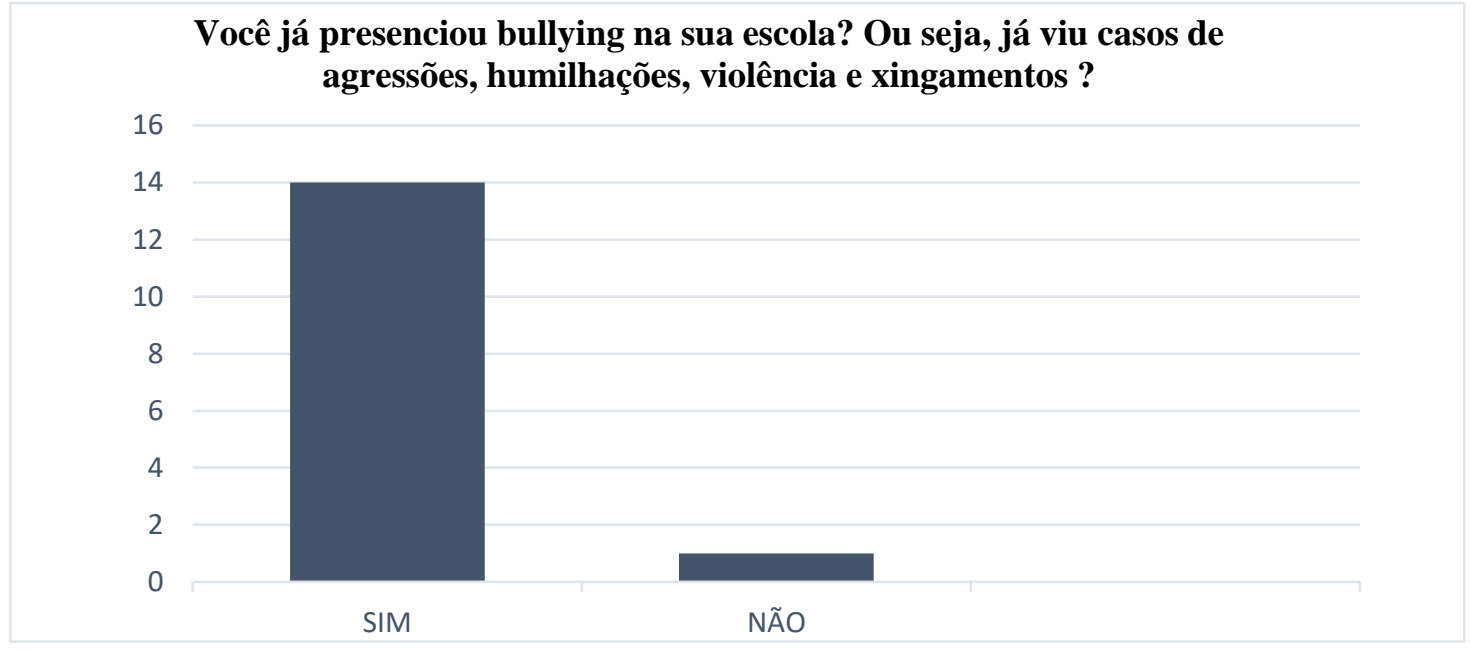

Fonte: Elaborado pelas autoras.

Isto posto, analisou-se que dos quinze alunos que responderam à questão catorze deles já presenciaram esse tipo de violência na escola e principalmente na sala de aula, tendo testemunhados essa prática. Berger (2007, p. 42) nos diz: "a maioria das testemunhas não consegue apoiar ou auxiliar a vítima de bullying por não saber o que fazer, por ter medo de se tornar a próxima vítima ou por medo de fazer algo errado e causar ainda mais problemas". Nota-se que o contato com bullying acontece mesmo sem ser em posição de vítima ou agressor, como adentra Lopes (2005, p. 9). "o simples testemunho de atos de bullying já é o suficiente para causar descontentamento com a escola e comprometimento do desenvolvimento acadêmico e social". 
Já as crianças que responderam à pergunta sobre se elas já haviam sido alvos de alguma violência, o mais calamitoso foi o fato de $100 \%$ delas terem marcado a alternativa que constava a resposta "sim". Ou seja, todos os alunos que se encontravam na sala já haviam sido xingados, violentados ou perseguidos. Além disso, dez destes alunos confirmaram que o bullying ocorria em sala, sendo que um deles marcou que já aconteceu em vários espaços da escola: no recreio, sala de aula, nos banheiros e durante a aula de educação física, enquanto um respondeu no banheiro e outro somente durante o recreio, e apenas um deles não se posicionou sobre a questão.

Durante as observações foram presenciadas cenas de agressão verbal e física, além da indisciplina e a falta de atenção por parte de alguns alunos durante a aula ministrada pela professora. Esse tipo de conduta se intensificou durante a educação física, pelo fato de haver crianças tanto com pouco preparo físico quanto com sobrepeso, estas foram as mais atacadas com xingamentos e chateações. Souza e Gonçalves (2021) ressaltam que a gordofobia também se enquadra como bullying e, ainda, alerta que isso pode interferir de forma direta no desenvolvimento das funções psíquicas da vítima. A gordofobia é movida pelo peso do indivíduo, que passa a ser alvo de ações de exclusão, violência e discriminação. Nesse sentido, os estudantes que não atendem ao padrão corporal, isto é, que apresentem sobrepeso e até mesmo a obesidade, são passíveis de sofrerem qualquer tipo de perturbação, resultando nos casos de gordofobia.

Além disso, foi anotado que alguns dos alunos, durante a resolução do questionário, apontaram um dos colegas como sendo o agressor, ou seja, aquele que frequentemente praticava esse tipo de agressão e persistia com essa prática, o que foi confirmado pelas observações registradas em diário de campo. Além disso, foi possível perceber que esta mesma criança apontada como agressora, a cada instante agredia alguém e, principalmente, o colega que sentava ao seu lado. Segundo relatos da vice-diretora ${ }^{1}$, este aluno já foi vítima de várias transferências e, na atual escola acumula algumas advertências devido às constantes brigas com determinados colegas.

Ao ser entrevistada sobre o que ocorre nas dependências da escola a vicediretora quando questionada sobre o bullying praticado e sofrido em locais como salas de aula e na escola, fez o seguinte relato:

É como eu digo, o apoio pedagógico é muito atuante aqui na escola, então, quando acontece esses conflitos a direção chama e a gente se reúne com o apoio pedagógico, com o professor pra poder apurar, ver os dois lados da história, ver como as coisas aconteceram pra gente poder tomar alguma atitude. (Sic). (Vicediretora).

Percebe-se que a gestão da escola não apresenta um plano de enfrentamento às agressões sofridas pelos alunos e alunas, tampouco aponta

\footnotetext{
${ }^{1}$ Será citado apenas o cargo que a entrevistada exerce, e não o nome, em vista da importância ética de preservar sua identidade.
}

Perspectivas em Diálogo, Naviraí, v. 09, n. 19, p. 140-158, jan./abr. 2022. 
nenhuma referência ao projeto pedagógico da escola como catalisador do currículo e de práticas descolonizadoras de educação. Um pouco mais à frente, ao ser indagada sobre a ocorrência de algum caso que tenha vindo a afetar a vida acadêmica do aluno ou que fez a criança evitar a escola, ela respondeu:

Tem essa questão da violência, pode ser que o bullying entre nessa questão aí de insulto e desse tipo de coisa né, mas assim, nunca veio um caso específico do menino vim dizer que não queria por isso e por aquilo, eles devem sentir e nem falar né, que é o pior. (Sic). (Vice-diretora) (Grifos nossos).

Neste trecho percebemos o silenciamento imputado pela opressão às vítimas e, mais grave ainda, o desconhecimento pela direção do que seja o conceito, a legislação e a prática do bullying no cotidiano dessa escola. A fala da entrevistada mostrou preocupação diante desses acontecidos, mas, também, uma impotência frente ao problema.

Contudo, o maior índice dos casos de bullying na escola passam despercebidos ou são mantidos em segredo durante muito tempo. Devemos estar atentos a determinados comportamentos e obter o maior número de informações junto a outros alunos e aos pais quanto às mudanças ou sinais que possam identificar com maior eficiência as possíveis vítimas (BARROS; CARVALHO E PEREIRA, 2009, p. 14).

Nesse contexto, foi perguntado aos alunos no questionário se eles haviam socializado sobre o bullying que haviam sofrido ou praticado para alguma pessoa. As respostas mostraram que oito dos alunos haviam falado para alguém, contudo, sete deles afirmaram que não, enquanto os outros sete responderam que já praticaram bullying com algum colega da escola e oito negaram que já violentaram alguém.

É notável que o medo e a intimidação transcorrem por esse lugar, mas o problema de não existirem casos específicos e relatos sobre o bullying com as autoridades escolares e a família não muda o fato de que pode sim existir casos de bullying que se ocultam pela intimidação por parte dos alunos, como foi constatado no questionário que sete dos quinze alunos responderam que não haviam falado com ninguém sobre a perseguição que sofriam, reforçando mais uma vez o silenciamento dos alunos, evidenciado na fala da vice gestora da escola. Em virtude disso, foi questionado como eles se sentiam quando o bullying acontecia, um deles optou por não responder, três mencionaram que não se incomodavam, dois disseram que se sentiam assustados, quatro com medo e cinco marcaram a alternativa que representava que não queriam ir mais para a escola. Veja-se o gráfico abaixo: 


\section{Gráfico 2 - Sentimentos das vítimas de bullying}

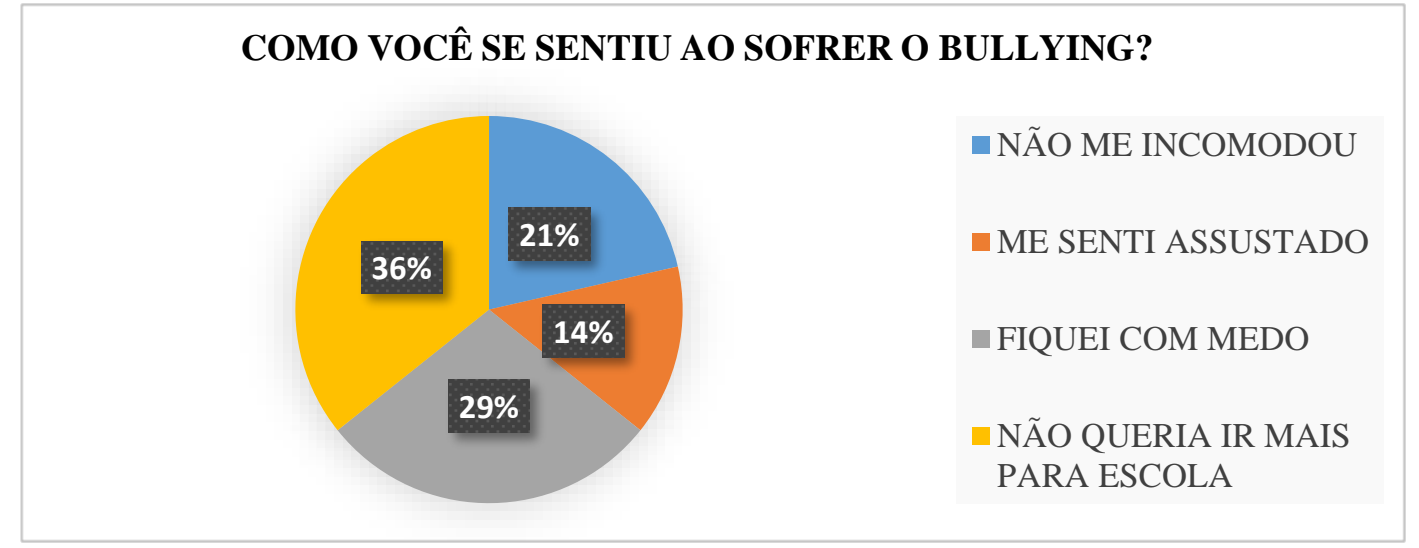

Fonte: Elaborado pelas autoras.

Pelo gráfico evidencia-se que esses fatores encaminharam essas crianças para consequências no desenvolvimento escolar, de tal forma a interferir no desempenho em atividades em sala, participação nas aulas e em outras ocasiões que resultavam na exposição da criança para os presentes na sala de aula. Segundo Lopes Neto (2005), sinais como medo e a recusa em se fazer presente nas aulas poderá influenciar, consideravelmente, nos rendimentos da criança, afetando sua participação nas atividades escolares individuais e em grupo, a evasão escolar e o isolamento. Nos casos mais graves, essa violência pode se associar à ansiedade, depressão e aparecimento de outras doenças psíquicas.

Outrossim, é que a turma estudada se mostrou envolvida em um contexto de convívio que compromete diariamente a harmonia e o envolvimento entre o grupo da sala. Isso pôde ser confirmado ao perguntar aos alunos: Que tipo de bullying você sofreu? Diante disso, quatro dos catorze alunos que responderam à questão apontaram que haviam sido alvos de risadas e apelidos, se equiparando aos outros quatro que marcaram que sofriam agressões. Ninguém respondeu que havia sido ameaçado e dois marcaram a alternativa que constava que já tinham contado fofocas/mentiras ao seu respeito. Por fim, dois optaram por marcar duas alternativas que se relacionavam à violência psicológica, isto é, aos apelidos e risadas juntamente com as mentiras/fofocas espalhadas sobre 0 aluno. Um deles também selecionou todas as alternativas.

Nesse contexto é necessário impulsionar o tema a fim de debatê-lo de forma mais profunda nos vários contextos da escola: Nos encontros de estudo e de formação continuada de professores; no interior das salas de aula; constituir projetos pedagógicos coletivos em que as temáticas: bullying, racismo, preconceito estejam alinhadas a projetos e práticas efetivas. Faz-se muito importante estabelecer a relação escola-comunidade e envolver as famílias no que diz respeito a temática e a importância da conscientização e do combate a esse tipo de agressão, assim como Bandeira, Hutz (2010, p. 42) nos adverte: 
[...] Conscientização por parte de alunos, pais, escola e comunidade de que o bullying é um problema sério e, como tal, não deve ser tolerado. O fato de muitos alunos perceberem 0 bullying como uma brincadeira alerta para a naturalização de um fenômeno grave e frequente no cenário escolar. Alerta também para a preponderância de um modelo individualista e a falta de sentimento de coletividade presente nos relacionamentos.

A promoção de uma rede de relações ancoradas na empatia e na boa convivência é primordial no combate a qualquer tipo de violência, inclusive, o bullying. Seja no contexto escolar, trabalho ou em qualquer âmbito, faz-se necessário a conscientização e o desenvolvimento do sentimento de coletividade. Aos professores e futuros professores, cabe o compromisso e o trabalho com temas como esse em sala de aula, bem como, outras temáticas que revelem importância histórica e social.

\section{Resultados e Possibilidades}

Este estudo, guarda relevância por apontar as evidências do bullying no cotidiano da escola, mas, principalmente, por sinalizar ações que podem contribuir para a educação anti-bullying ao qual deve perpassar todo o currículo escolar e estar alinhado à Lei n. 13.185, de 06.11.2015, um marco jurídico de combate ao bullying e a primeira lei nacional que tem como objetivo prevenir e combater a prática da intimidação sistemática no País. A pesquisa evidencia como consequências do bullying o medo, a insegurança no ambiente escolar, o desejo de abandono dos estudos e nos mostra que:

a.) No universo pesquisado, $100 \%$ dos estudantes pesquisados já foram vítimas de bullying na escola, portanto, todos, sem exceção;

b.) Destes, $29 \%$ ficaram com medo e $14 \%$ disseram ficarem assustados com tais práticas, totalizando $43 \%$ de pessoas com medo de estarem no ambiente escolar. Isso significa dizer que a escola não representava um lugar seguro para essas crianças;

c.) Um total de $36 \%$ não queriam mais ir para a escola, e, por limitação deste estudo, uma dúvida se apresenta: Quanto destes alunos se evadiram da escola durante o ano letivo?

d.) As práticas de bullying retratadas na empiria revelam que a humilhação, xingamentos, risadas seguidas de depreciação, são uma constante no cotidiano da escola, práticas estas que podem contribuir para a formação de identidades cambiantes, baixa autoestima e dificuldades na relação com a própria aprendizagem.

e.) Mentiras e "fofocas" práticas recorrentes no universo pesquisado, podem afetar a dignidade da pessoa humana e abrem brechas ao desrespeito do grupo para com a vítima, pois, altera a forma como a pessoa é vista na comunidade escolar.

f.) Essas práticas de bullying passam despercebidas pela gestão da escola estudada, portanto, ações precisam ser efetivadas, tais como as que são apontadas nos itens seguintes. 
A seguir, a partir dos evidentes resultados aqui mencionados, sugerese possibilidades de práticas que vão ao encontro de uma educação antibullying, tais como:

- Observação intencional das áreas externas à sala de aula entendidos como espaços sociais tais como pátio, locais de merenda/refeitórios, banheiros, quadras esportivas, locais e de lazer e brincadeiras: Crianças isoladas devem ser motivo de atenção do corpo docente, e mais ainda, da gestão escolar. A aproximação a esses alunos deve ser pensada no coletivo, para que possam se abrir acerca da causa do isolamento.

- (Assumpção), visibilização a toda a comunidade escolar acerca da existência de práticas nocivas de bullying entre as crianças, para, assim, oferecer o suporte necessário às vítimas;

- A escola deve primar pela promoção de Grupos de Estudo sobre conceitos, caracterização e práticas de bullying a partir de literatura da área;

- A escola deve possibilitar a organização de projetos de ensino voltados

a uma educação anti-bullying, os quais devem permear o currículo;

- Criação de canais de ouvidoria para que as vítimas possam denunciar o assédio de bullying que sofrem nos espaços da escola ou em continuidade a este, como no caso do ciberbullying;

- Desenvolvimento de políticas de acompanhamento do desempenho escolar dos alunos de maneira geral, e mais especificamente, das vítimas de bullying no que se refere ao rendimento nas avaliações e frequência escolar;

- Atualização do projeto político pedagógico da escola, tendo o bullying, racismo, homofobia e outros temas que incluam diferentes formas de subalternização como pauta para projetos coletivos de educação crítica e emancipadora.

- Realização de trabalho educativo junto às famílias tanto das vítimas quanto dos agressores acerca das causas e consequências do bullying para a vida presente e futura as crianças.

\section{Considerações Finais}

O estudo que ora se conclui se propôs a responder à seguinte problematização: "Quais as consequências e prejuízos que o bullying pode provocar na vida do discente e, mais especificamente, como a escola pode se aparelhar para combater o bullying em seu cotidiano?"

Para responder a tal indagação, partiu-se da busca do conhecimento acerca da temática, isto é, de seus aspectos conceituais e descritivos, de modo a evidenciar também a interferência desse tipo de violência no interior do ambiente escolar. Apresentou-se 0 perfil das vítimas com enfoque nas consequências provindas dessa prática que, por sua vez, afeta, 
substancialmente, a vida do sujeito em diferentes instâncias e, possivelmente, etapas de vida.

Ao conceituar essa prática foi possível caracterizá-la como sendo violência física e psicológica que ocorre com um determinado indivíduo de forma constante, mostrando-se o quão conflituoso podem ser as relações interpessoais dentro da escola. Além disso, foi importante entender que há diferenças entre bullying, a violência escolar e o preconceito, sendo a vítima do bullying alunos e alunas que passam a ser alvo da violência em decorrência de seu perfil considerado fraco, muitas vezes por apresentarem alguns atributos não comuns aos demais colegas, são escolhidos para serem ponto de humilhações, apelidos, xingamentos e situações vergonhosas. Porém, sua cor e seus atributos, em grande parte, não são motivos de ódio e aversão como o do preconceito racial, por exemplo, mas são vistos como características magoáveis para o agressor e que perdura por muito tempo, esse longo período é o que diferencia da violência escolar.

Assim, tendo a escola " $X$ " como lócus supõe-se, que conflitos são inerentes à vida social das crianças na escola, porém, quando envolvido de violência física, psicológica, perseguições, passam a ser motivos de preocupações. À vista disso, diante desses atos há legislações que punem e intensificam o combate, sendo o bullying uma prática de procedência e preocupação mundial o Brasil trata disso utilizando-se da Lei no 13.185 de 6 de novembro de 2015, que Institui o Programa de Combate à Intimidação Sistemática (Bullying), com vistas a assegurar a proteção da criança na escola.

Dessa forma, tendo em vista os dados empíricos procedentes da entrevista com a gestão escolar bem como os resultados apresentados por questionário aplicado às crianças, faz-se necessário apontar que a gestão está permeada pelo silenciamento e desconhecimento de casos não diretamente notificados, de modo a não apresentar um plano de enfrentamento desses casos que funcione efetivamente. Os alunos e alunas, vítimas das práticas de bullying, por medo de serem vítimas de mais violência e por se sentirem-se desprotegidos pela instituição-escola, também silenciam. Em decorrência, o estudo constatou a ausência de um Projeto Político Pedagógico que atenda a complexidade do bullying no cotidiano escolar e, além do mais, que interseccione essa violência e aborde os casos de preconceito, racismo, homofobia, etc. Resulta-se em uma dinâmica escolar movida pelo medo, susto, desestímulo, evasão escolar, identidades fragilizadas, ansiedades e o progressivo aumento de relações interpessoais instáveis e conturbadas entre os estudantes.

Tendo como base nas evidências, o estudo aponta algumas possibilidades de intervenção da escola com vistas a se combater o bullying tais como: constate atualização do projeto pedagógico para se incluir projetos de ensino críticos e emancipadores, fortalecimento de grupos de estudo para se conhecer e caracterizar melhor o bullying e assim, identificá-lo no cotidiano da escola e, ainda, a educação das famílias, mostrando-Ihes as consequências das práticas do bullying para a vida escolar atual e para o futuro, na vida adulta, dos filhos. 
Conclui-se, dessa forma, que o bullying se manifesta e se expande em vários contextos sociais, sendo a escola o principal deles. Foi percebível que alguns alunos do $4^{\circ}$ ano da Escola $X$ se encontram na condição de alvos desse tipo de violência, sentindo-se amedrontados, vulneráveis e sem um suporte da instituição escolar para a resolução deste problema. Logo, é nítido que o contexto escolar estará sempre tomado de crianças que perpassaram sua trajetória escolar de forma traumatizante e negativa, a menos que haja uma conscientização por parte de todos.

Ao final deste estudo, novas indagações emergem, tais como: Vítimas de bullying na infância podem demonstrar comprometimento dos rendimentos escolares? O bullying abre brechas a transtornos psíquicos na vida adulta em consequência desse tipo de violência? Tais questionamentos sugerem, em continuidade a esta pesquisa, estudos de caráter longitudinal e em intersecção com mais de uma área de conhecimento, como por exemplo educação, psicologia e medicina.

Finaliza-se este texto com as palavras de Silva (2010, p.13): "cabe à sociedade como um todo transmitir às novas gerações valores educacionais mais éticos e responsáveis [...] Auxiliá-los e conduzi-los na construção de uma sociedade mais justa e menos violenta, é obrigação de todos".

\section{REFERÊNCIAS}

ALMEIDA, Ana Rita Silva. Emoção na sala de aula. 6. ed. São Paulo: Papirus. 2007.

BANDEIRA, Cláudia de Moraes; HUTZ, Claudio Simon. Bullying: prevalência, implicações e diferenças entre os gêneros. Psicologia Escolar e Educacional (Impresso), v. 16, p. 35-44. 2012.

BARROS, Paulo Cesar; CARVALHO, João Eloir; PEREIRA, Maria Beatriz Ferreira Leite Oliveira. Um estudo sobre bullying no contexto escolar. IX Congresso Nacional de Educação - EDUCERE III Encontro Sul Brasileiro de Psicopedagogia - PUCPR. 2009.

BERGER, Kathleen Stassen. Update on bullying at school: Science forgoten? Developmental Review, v. 27, n. 1, p. 90-126, 2007.

BRASIL. Lei n. ${ }^{013.185}$, de 6 de novembro de 2015. Institui o Programa de Combate à Intimidação Sistemática (Bullying). Disponível em: http://www.planalto.gov.br/ccivil_03/_Ato2015-2018/2015/Lei/L13185.htm Acesso em: 21 maio 2020.

ECHER, Isabel Cristina. A revisão de literatura na construção do trabalho científico. Revista Gaúcha Enfermagem, Porto Alegre, v. 22, n. 2. 2001. 
FREIRE, Paulo. Pedagogia da Autonomia: Saberes Necessários à prática educativa. $41^{a}$ reimpressão. São Paulo: Paes e Terra. 1996.

GIL, Antônio Carlos. Métodos e técnicas em pesquisa social. 5. ed. São Paulo: Atlas. 1999.

IBGE, Instituto Brasileiro de Geografia e Estatística. Pesquisa nacional de saúde escolar. Rio de Janeiro: Instituto Brasileiro de Geografia e Estatística. 2016.

JAHNKE, Letícia Thomasi; GAGLIETTI, Mauro. O avanço tecnológico e os conflitos comportamentais nas redes sociais - o cyberbullying. In: $1^{0}$ Congresso Internacional de Direito e Contemporaneidade da UFSM. Anais... Santa Maria RS, UFSM, 2012.

LOPES NETO, Aramis. Bullying: Comportamento Agressivo entre Estudantes. Jornal de Pediatria, (Rio J.) $n^{\circ} .81, \mathrm{n}^{\circ} .5$ supl. Porto Alegre nov. 2005.

OLWEUS, Dan. Conductas de acaso y amenaza entre escolares. Madri: Morata. 1998.

SAVAZZONI, Simone de Alcantara. Preconceito, racismo e discriminação. Revista do Curso de Direito da Faculdade de Humanidades e Direito, São Paulo, v. 12, n. 12, p. 39- 75, 2015.

SILVA, Ana Beatriz Barbosa. Bullying. Cartilha 2010-Projeto Justiça nas Escolas. Brasília: Conselho Nacional de Justiça. 2010.

SOUZA, Valdelice Cruz da Silva; GONÇALVES, Josiane Perez. GORDOFOBIA NO ESPAÇO ESCOLAR: uma análise histórico-cultural. Revista Ciências Humanas, [S. I.], v. 14, n. 1, 2021. Disponível em: https://www.rchunitau.com.br/index.php/rch/article/view/701. Acesso em: 29 set. 2021.

TRIVINÕS, Augusto Nibaldo Silva. Introdução à pesquisa em ciências sociais: a pesquisa qualitativa em educação. São Paulo, Atlas. 1987. 